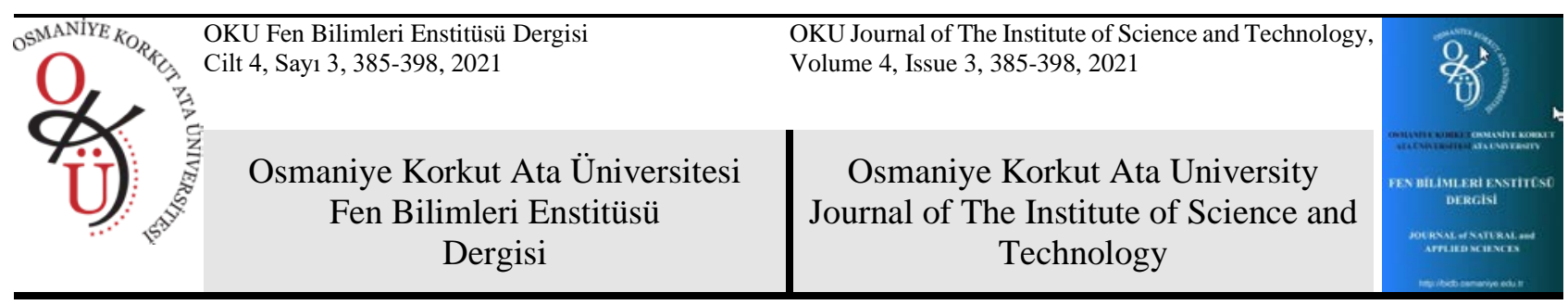

\title{
S-Tipi Granitlerdeki Beyaz Mikaların Raman Karakteristikleri: Yozgat İntrüzif Kompleksi’nin Kuzey Bölümü
}

\author{
Musa Avni AKÇE ${ }^{1 *}$, Yusuf Kağan KADIOĞLU' \\ ${ }^{1}$ Nevşehir Hacı Bektaş Veli Üniversitesi, Mühendislik-Mimarlık Fakültesi, Jeoloji Mühendisliği Bölümü, 50300, Nevşehir \\ ${ }^{2}$ Ankara Üniversitesi, Mühendislik Fakültesi, Jeoloji Mühendisliği Bölümü, 06830, Ankara \\ ${ }^{3}$ Ankara Üniversitesi, Yer Bilimleri Uygulama ve Araştırma Merkezi (YEBİM), 06830, Ankara \\ ${ }^{1}$ https://orcid.org/0000-0002-9180-7015 \\ 2,3https://orcid.org/0000-0002-7894-2220 \\ *Sorumlu yazar: akce@nevsehir.edu.tr
}

\section{Araştırma Makalesi}

\section{Makale Tarihçesi:}

Gelis tarihi: 17.08.2021

Kabul tarihi:12.10.2021

Online Yayınlanma: 15.12.2021

\section{Anahtar Kelimeler:}

Raman spektroskopisi

Beyaz mika

Fillosilikatlar

S-tipi granit

Yozgat İntrüzif Kompleksi

\section{ÖZET}

S-tipi granitler genel olarak kıta-kıta çarpışması veya yitim kuşağının başlangıcında çarpışma ile eş zamanlı olarak oluşmaktadır. Bu granitler, üst kabuğun bindirme fay zonları boyunca $500-650{ }^{\circ} \mathrm{C}$ sicaklıklarda kısmi ergimesi sonucu oluşurlar. $\mathrm{Bu}$ kayaların ana kaynaklarını sedimanter ürünler oluşturduğundan dolayı S-tipi granitler şeklinde adlandırılırlar. S-tipi granitler el örneklerinde açık renkli, faneritik dokulu olup başlıca kuvars, K-feldispat, beyaz mika (muskovit), anortit içeriği düşük plajiyoklaz (çoğunlukla oligoklaz ve albit bileşimli) ve az miktarda siyah mikadan (biyotit) oluşmaktadırlar. Yozgat İntrüzif Kompleksi'nin kuzey-kuzeybatı bölümünde yer alan granitler S-tipi granit bileşiminde olup başlıca kuvars, ortoklaz, muskovit ve az oranda oligoklaz, albit ve biyotitten oluşmaktadır. Bu çalışmada Stipi granitler içerisindeki muskovitlerin Raman karakteristikleri belirlenmiştir. Muskovitlerin Raman spektroskopik ölçümleri sonucunda $50-1250 \mathrm{~cm}^{-1}$ ve 2800 $3623 \mathrm{~cm}^{-1}$ dalga sayısı aralıklarındaki spektrumları elde edilmiştir. Bu spektral verilere göre, belirgin Raman kayma değerlerinin görüldüğü spektral bölgeler tespit edilmiş̧ir. 1200-875 $\mathrm{cm}^{-1}$ arasındaki spektral bölgede $\mathrm{Si}-\mathrm{O}-\mathrm{Si}(\mathrm{Al})$ gerilme titreşimlerini temsil eden bantlar bulunmaktadır. $750-650 \mathrm{~cm}^{-1}$ arasındaki spektral bölgede $\mathrm{O}-\mathrm{Al}-\mathrm{O}$ bükülme titreşimlerinden kaynaklanan bantlar görülmektedir. $500-225 \mathrm{~cm}^{-1}$ arasindaki spektral bölgede, başlica $\mathrm{O}-\mathrm{Al}-\mathrm{O}$ ve $\mathrm{O}-\mathrm{Si}-\mathrm{O}$ translasyonları ile ilişkili karışık karaktere sahip bantlar mevcuttur. $225-75 \mathrm{~cm}^{-1}$ arasındaki spektral bölgede $\mathrm{Al}-\mathrm{OH}$ ve levha translasyonlarına bağlı bantlar gözlenir. 2800-3623 $\mathrm{cm}^{-1}$ arasındaki spektral bölgedeki bantların ise O-H ya da C-H gerilme titreşimlerinden kaynaklanan bantlarla örtüşebileceği görülmüştür. Böylece, S-tipi granitlerdeki muskovitlerin Raman spektrum özelliklerinin granitlerin kökeni ve kaynağının belirlenmesinde kullanılmasının mümkün olabileceği ortaya konmuştur.

\section{Raman Characteristics of White Micas within the S-Type Granites: Northern Part of Yozgat Intrusive} Complex

\section{Research Article}

Article History:

Received: 17.08 .2021

Accepted: 12.10 .2021

Published online: 15.12.2021

\section{Keywords:}

Raman spectroscopy

White mica

Phyllosilicates

S-type granite

Yozgat Intrusive Complex

\begin{abstract}
S-type granites are generally formed simultaneously with continent-continent collision or syn-collision related to the beginning of the subduction zone. These granites are formed as a result of partial melting of the upper crust at temperatures of $500-650{ }^{\circ} \mathrm{C}$ along the thrust fault zones. They are called S-type granites because the main sources of these rocks are sedimentary products. S-type granites have a light colored, phaneritic texture in hand specimens, consist mainly of quartz, Kfeldspar, white mica (muscovite), plagioclase with low anorthite content (mostly in oligoclase and albite composition) and with rare amount of black mica (biotite). The granites located in the north-northwest part of the Yozgat Intrusive Complex are formed S-type granite composition and consist mainly of quartz, orthoclase, muscovite and rare amount of oligoclase, albite and biotite. In this study, Raman
\end{abstract}


characteristics of the muscovites within the S-type granites were determined. As a result of Raman spectroscopic measurements of muscovites, their spectra in wavenumber ranges of $50-1250 \mathrm{~cm}^{-1}$ and $2800-3623 \mathrm{~cm}^{-1}$ were obtained. According to these spectral data, spectral regions with significant Raman shift values were determined. There are bands representing $\mathrm{Si}-\mathrm{O}-\mathrm{Si}(\mathrm{Al})$ stretching vibrations in the spectral region between $1200-875 \mathrm{~cm}^{-1}$. In the spectral region between $750-650 \mathrm{~cm}^{-}$ ${ }^{1}$, bands originating from $\mathrm{O}-\mathrm{Al}-\mathrm{O}$ bending vibrations are seen. In the spectral region between $500-225 \mathrm{~cm}^{-1}$, there are bands having mixed character mainly associated to $\mathrm{O}-\mathrm{Al}-\mathrm{O}$ and $\mathrm{O}-\mathrm{Si}-\mathrm{O}$ translations. In the spectral region between $225-75 \mathrm{~cm}^{-1}$, bands are observed related to $\mathrm{Al}-\mathrm{OH}$ and sheet translations. It has been seen that the bands in the spectral region between $2800-3623 \mathrm{~cm}^{-1}$ may overlap with the bands originating from $\mathrm{O}-\mathrm{H}$ or C-H stretching vibrations. Thus, it has been demonstrated that it is possible to use the Raman spectrum properties of muscovites in S-type granites to determine the nature and source of the granites.

To Cite: Akçe MA., Kadığlu YK. S-Tipi Granitlerdeki Beyaz Mikaların Raman Karakteristikleri: Yozgat İntrüzif Kompleksi’nin Kuzey Bölümü. Osmaniye Korkut Ata Üniversitesi Fen Bilimleri Enstitüsü Dergisi 2021; 4(3): 385-398.

\section{Giriş}

Raman saçılması, ilk defa ünlü Hint fizikçi Sir Chandrasekhara Venkata Raman (1888-1970) tarafından 1928'de keşfedilmiştir. Raman saçılmasının incelenmesi ile moleküllerin kimyasal yapısı hakkında önemli bilgiler elde edilmektedir. Raman saçılmasını temel edinen Raman spektroskopisi, inorganik ve organik örneklerin kalitatif ve kantitatif analizinde kullanılabilen oldukça pratik ve hızlı, örneği tahrip etmeden uygulanabilen çok önemli bir spektroskopik yöntemdir (Smith ve Dent, 2019).

Raman titreşimsel bantları; frekansı (enerjisi), şiddeti (polar karakter veya polarlanabilirlik) ve bant şekilleri (bağların ortamı) ile karakterize edilirler. Titreşimsel enerji seviyeleri her bir moleküle özgü olduğundan, Raman spektrumu belirli bir molekülün "parmak izini” sağlar. Bu moleküler titreşimlerin frekansları; atomların kütlelerine, geometrik düzenlemelerine ve kimyasal bağlarının gücüne bağlıdır (Larkin, 2011). Ancak enstrümantal kurulum, yapısal kusurlar, eser elementler, iç gerilmeler ya da sıcaklık gibi farklı parametreler Raman sinyalini etkileyebilmektedir (Foucher ve ark., 2013) (Şekil 1).

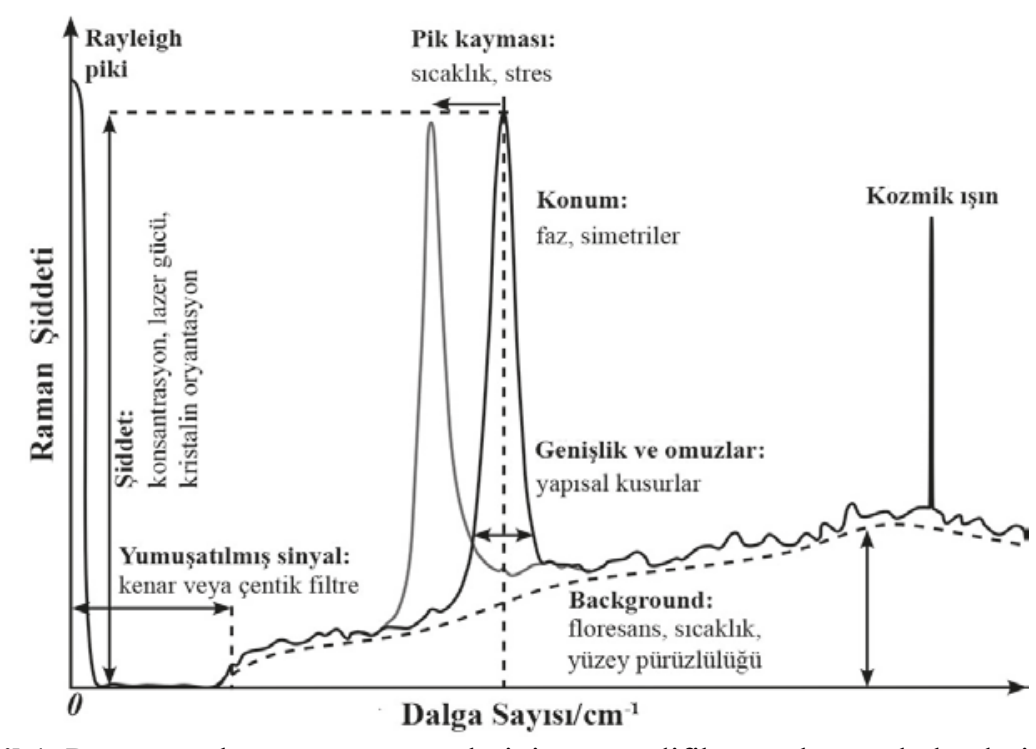

Şekil 1. Raman spektrumu parametrelerinin ve modifikasyonlarının kökenleri (Foucher ve ark. (2013)'den değiştirilerek alınmıştır).

Birçok farklı alanda kullanılan Raman spektroskopisi mineralojik incelemelerde de özellikle mineral tayinine yönelik olarak kullanılmakta olup çok doğru ve başarılı sonuçlar elde edilmektedir (Griffith, 1974; McMillan 
ve Hofmeister, 1988; Nasdala ve ark., 2004; Foucher ve ark., 2013, 2017; Fries ve Steele, 2018; Akçe ve Kadığlu, 2020; Chukanov ve Vigasina 2020). Konfokal Raman Spektroskopisi (KRS); mineralojik ve petrolojik çalışmalarda rutin optik mikroskop, kimyasal analiz, X-1şını difraktometre (XRD) ve elektron prob mikroanaliz (EPMA) gibi diğer spektroskopik incelemeleri desteklemekte ve hatta tamamlamaktadır.

Farklı mineral ve mineral gruplarının Raman spektroskopik karakteristikleri üzerine yapılmış muhtelif çalışmalar bulunmaktadır. Silikatların ana yapısal tiplerinden biri olan fillosilikatlar, oldukça değişken yapılara ve çok karmaşık kimyaya sahip olup literatürde farklı yapı ve bileşimdeki fillosilikat minerallerinin Raman spektroskopileri üzerine de yapılmış birçok çalışma mevcuttur (Loh, 1973; Blaha ve Rosasco, 1978; Wada ve Kamitakahara, 1991; Frost, 1995; Frost ve Rintoul, 1996; Frost ve Van der Gaast, 1997; Farmer, 1998; Frost ve Kloprogge, 2000; Kloprogge ve Frost, 2000; Rinaudo ve ark., 2003; Petry ve ark., 2006).

Son yıllarda ülkemizde, özellikle magmatik ve metamorfik kayalarda bulunan minerallerin Raman spektrumları kullanılarak magmanın kristalleşme süreçlerindeki değişimler ve metamorfizma koşullarının yorumlanmasına yönelik çalışmalar ağırlık kazanmıştır (Zoroğlu ve Kadığlu, 2007; Akçe ve Kadıŏlu, 2009a,b; Güllü ve Kadığlu, 2009; Akçe, 2010; Deniz, 2010; Kadığlu ve ark., 2011; Deniz ve ark., 2013; Koralay ve ark., 2013; Güllü ve Kadığlu, 2017; Güllü ve ark., 2019; Kadıoğlu ve ark., 2019; Akçe ve Kadıŏlu, 2020, Koralay ve Ören, 2020; Deniz 2021).

Çalışma alanı, bölgesel jeolojik konum açısından literatürde Orta Anadolu Masifi (Ketin, 1955), Kırşehir Masifi (Seymen, 1981), Kırşehir Bloğu (Görür ve ark., 1984), Kırşehir Karmaşığı (Lünel, 1985) ve Kırşehir Mikrolevhası (Norman ve ark., 1980) olarak da adlandırılan Orta Anadolu Kristalen Karmaşığı (Göncüoğlu ve ark., 1991) içerisinde yer almaktadır. Orta Anadolu Kristalen Karmaşı̆̆ı (OAKK), Orta Anadolu'da kuzeyde İzmir-Ankara-Erzincan sütur zonu, batıda Tuz Gölü fayı, doğuda ise Ecemiş fay zonuyla sınırlanan ve kabaca üçgen biçimli geniş bir alanda yayılım gösteren magmatik ve metamorfik kayalar topluluğundan oluşmaktadır (Şekil 2). Bölgenin temelini metamorfik birimler ile mafik ve felsik intrüzif kütleler oluşturmaktadır. Bu temel, genç çökel ve volkanik birimler tarafından örtülmektedir. Metamorfik birimler, bölgenin daha çok kuzey kesiminde gözlenirken tabanda amfibolit fasiyesi ile başlayıp yeşilşist fasiyesi ile devam etmekte ve üstte mermerler yer almaktadır. Mafik kütleler intrüzif gabrolar ile ofiyolitik gabro, diyabaz ve bazalt bileşimindeki Mesozoyik ofiyolitik seri kayalarından oluşmakta, yine bölgenin daha çok kuzey bölümünde gözlenmekte ve kuzeyden başlayıp batı ve güneydoğuya doğru bükülerek bir yay şeklinde devam etmektedirler. Felsik kütleler ise kendi içerisinde yaşlıdan gence doğru granitik, monzonitik ve siyenitik bileşimde ve kalkalkaliden alkaliye doğru değişen bir magmatik karakter sergilemekte olup bu felsik plütonlar ve bunlarla ilişkili damar karşıtları hem metamorfik temeli hem de ofiyolitik seriyi kesmiştir.

Önceki çalışmalarda Yozgat Batoliti ve Kompozit Yozgat Batoliti gibi isimlerle de anılan Yozgat İntrüzif Kompleksi (YİK), OAKK'nın kuzey bölümünde yer almakta olup farklı jeolojik, mineral topluluk ve jeokimyasal karakterdeki granitoyid, gabroyid, monzonit ve siyenitoyid bileşimindeki kayalardan oluşmaktadır (Boztuğ, 1994; Erler ve Göncüoğlu, 1996; Ekici ve Boztuğ, 1997; Tatar ve Boztuğ, 1998; Akçe, 2003; Akçe ve Kadığlu, 2004, 2005; Akçe, 2010; Deniz ve Kadıŏlu 2019). 


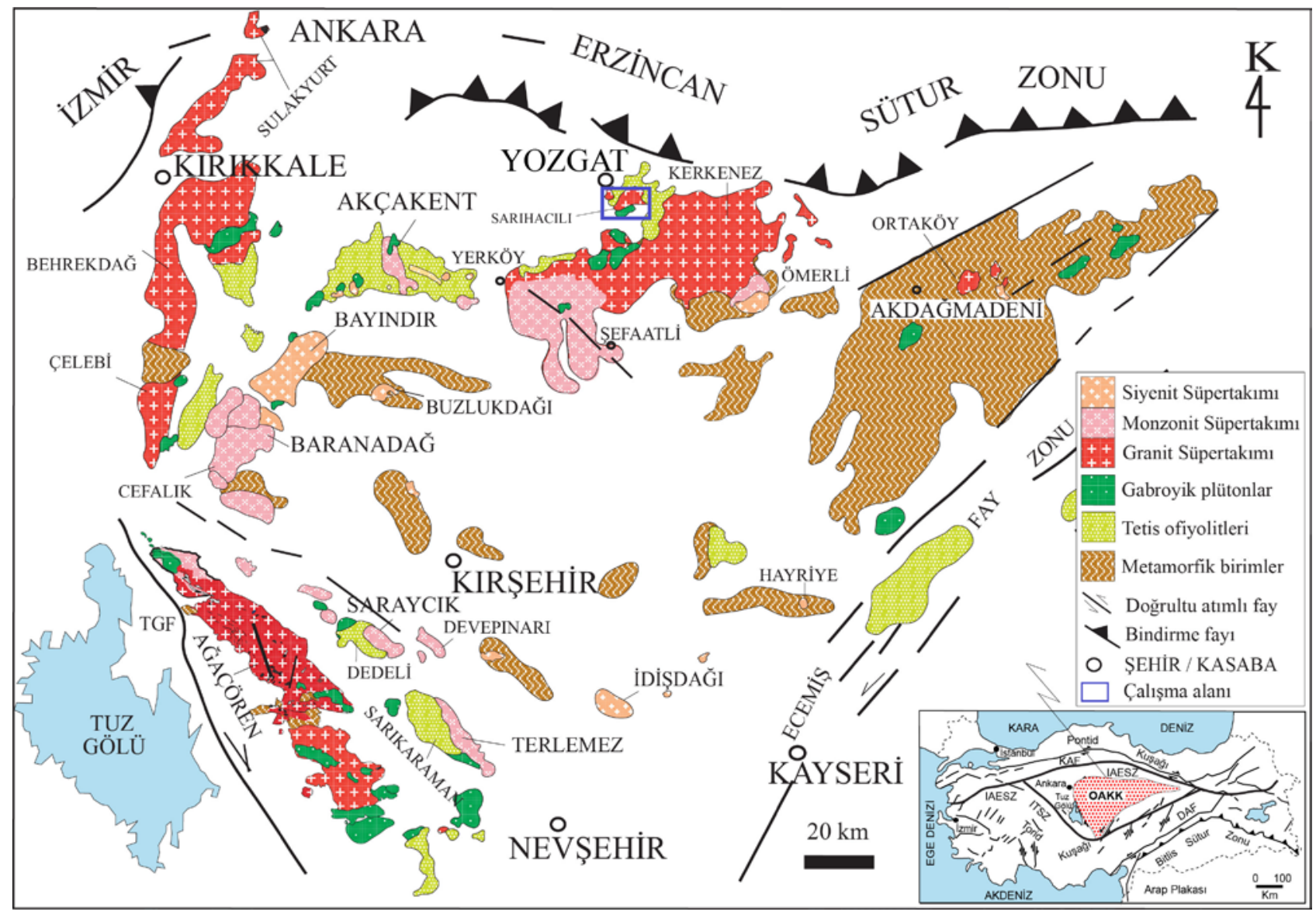

Şekil 2. Orta Anadolu Kristalen Karmaşı̆̆ı'nın basitleştirilmiş jeoloji haritası (OAKK: Orta Anadolu Kristalen Karmaşı̆̆ı, KAF: Kuzey Anadolu Fayı, DAF: Doğu Anadolu Fayı, ITTSZ: İç Toros Sütur Zonu, İAESZ: İzmir-Ankara-Erzincan Sütur Zonu) (Kadığlu ve ark. (2006)’dan değiştirilerek alınmıştır).

Bu çalışma kapsamında; YİK'nin kuzey bölümünde yer alan S-tipi granitler (Akçe, 2010) içerisinde gözlenen beyaz mikalar üzerinde analizler yapılmıştır. Genelde petrografik incelemelerde daha ayrıntılı mineralojik tanımlamalar yerine daha genel anlamda "beyaz mika" ifadesi kullanılır. Muskovit, kayalarda en yaygın gözlenen beyaz mikadır. Muskovitler, çoğunlukla magmatik ve metamorfik kayalarda ve kısmen de sedimanter kayalarda bulunmaktadır.

İncelenen bu minerallerin Raman spektrum sonuçları değerlendirilerek magmanın kristalleşme süreçlerindeki farklılıklar ortaya konulmaya çalışılmıştır. Ayrıca beyaz mikalarla ilgili literatürdeki Raman verileri ile karşılaştırılarak çalışma alanındaki beyaz mikaların Raman karakterizasyonu irdelenmiştir. Böylece beyaz mikaların KRS ile bileşimsel özellikleri belirlenerek yer aldıkları kayaların kökenleri ortaya konulmaya çalışılmıştır.

\section{Beyaz Mikaların Bulunduğu Kaya Tipleri}

Beyaz mikalar magmatik, metamorfik ve sedimanter kaya tiplerinde bulunabilmektedir. Magmatik kayalardan özellikle S-tipi granitlerde ve pegmatitlerde daha çok yer alan beyaz mikalar, volkanik kayalarda ise yer almamaktadır. Beyaz mikalar magmanın kristalleşmesinde, basıncın daha az olduğu durumlarda oluşmaktadırlar. Özellikle pegmatitlerde ana mineral olarak oluşurlar. 
Metamorfik kayalarda beyaz mikalar yeşilşist fasiyesinde metamorfizma koşullarının belirlenmesinde ana mineral rolü oynar. Bununla birlikte gömülme metamorfizmasında mavişist fasiyesinde mavi amfibollerle birlikte gözlenirler.

Sedimanter kayalarda özellikle kırıntılı kayalarda farklı oranlarda bulunabilmektedir. Bu yüzden beyaz mikaların Raman karakteristikleri kayanın oluşum koşullarının belirlenmesinde önemli rol oynar.

\section{Mikaların Raman Spektroskopik Karakteristikleri}

Fillosilikatlar ve özellikle mikaların Raman spektroskopik karakteristikleri üzerine farklı araştırmacılar tarafından yapılmış önemli çalışmalar mevcuttur (Loh, 1973; Tlili ve ark., 1989; Robert ve ark., 1993; McKeown ve ark., 1999a,b; Wang ve ark., 2002; Šontevska ve ark., 2008; Wang ve ark., 2015; Singh ve Singh, 2016).

Fillosilikatlar magmatik, metamorfik ve sedimanter süreçlerle oluşabilir. Fillosilikatlar son derece karmaşık yapılara ve spesifik kökenleriyle ilişkili olarak oldukça değişken bileşimlere sahiptirler. Fillosilikatlar, T ve Oc istiflenme dizilerinin farklı tiplerine göre beş farklı gruba ayrılabilirler. T: merkezi katyon olarak Si (ve bazen $\mathrm{Al}$ ) tarafından doldurulmuş tetrahedrayı temsil etmek için; Oc: merkezi katyon olarak $\mathrm{Mg}, \mathrm{Fe}^{2+}, \mathrm{Fe}^{3+}$ veya Al'lu oktahedrayı temsil etmek için kullanılmaktadır. Bu gruplar; kaolinit-serpantin grubu (T-Oc), pirofillit-talk grubu (T-Oc-T), mika grubu (T-Oc-T-A, A=K, Na), smektit grubu [T-Oc-T-B, B=Na, K, Ca, $\left.\mathrm{Li}, \mathrm{Mg}\left(\mathrm{H}_{2} \mathrm{O}\right)_{6}\right]$ ve klorit grubudur (T-Oc-T-Oc-T-Oc-T) (Wang ve ark., 2015). Bu minerallerin yapisalbileşimsel sınıflandırılması Tablo 1'de verilmiştir $(\mathrm{T}=$ tetrahedral tabaka, $\mathrm{O}=$ oktahedral tabaka, $\mathrm{A}=$ ara tabaka büyük katyon veya su) (Wang ve ark., 2002).

Fillosilikatlar, belirgin şekilde farklı istiflenme dizilerine sahip olup bunlardan mika grubu mineraller T-Oc$\mathrm{T}-\mathrm{A}(\mathrm{A}=\mathrm{K}, \mathrm{Na})$ şeklindedir. Muskovit $\left[\mathrm{KAl}_{2}\left(\mathrm{AlSi}_{3} \mathrm{O}_{10}\right)(\mathrm{OH})_{2}\right]$, filogopit $\left[\mathrm{KMg}_{3}\left(\mathrm{AlSi}_{3} \mathrm{O}_{10}\right)(\mathrm{OH})_{2}\right]$ ve biyotitin $\left[\mathrm{KFe}_{3}\left(\mathrm{AlSi}_{3} \mathrm{O}_{10}\right)(\mathrm{OH})_{2}\right]$ ortak yapısal özelliği; T-Oc-T tabakaları arasındaki boşluğa sıkıştırılmış A’nın (normalde $\mathrm{Na}^{+}$ya da $\mathrm{K}^{+}$) büyük katyonu ifade ettiği T-Oc-T -A istiflenme dizisidir (Wang ve ark., 2015).

Tablo 1. Yaygın fillosilikatların yapısal-bileşimsel sınıflandırılması (Wang ve ark., 2002)

\begin{tabular}{lll}
\hline & $\begin{array}{l}\text { Di-oktahedral } \\
\text { (O alanlarının 2/3 '̈̈nü Al doldurur) }\end{array}$ & $\begin{array}{l}\text { Tri-oktahedral } \\
\text { (O alanlarının tamamını Mg, Fe doldurur) }\end{array}$ \\
\hline T-O & Kaolinit & Serpantin \\
T-O-T & Pirofillit & Talk \\
T-O-T - A & Muskovit & Flogopit-Biyotit \\
T-O-T - A & Montmorillonit & Vermikülit \\
T-O-T-O-T-O-T & & Klorit \\
\hline
\end{tabular}

Fillosilikatların Raman spektrası genelde; 1) $3800-3000 \mathrm{~cm}^{-1}$, 2) $1150-800 \mathrm{~cm}^{-1}$, 3) $800-600 \mathrm{~cm}^{-1}$ ve 4) $<600$ $\mathrm{cm}^{-1}$ olmak üzere dört spektral bölgede gözlenir. 3800-3000 $\mathrm{cm}^{-1}$ spektral bölgesindeki Raman pikleri fillosilikat yapılarındaki OH ya da suyun gerilme modundan kaynaklanır (Wang ve ark., 2002, 2015).

Tlili ve ark., (1989), fillosilikatlardan mikaların Raman spektrasını; düşük dalga sayısı bölgesi (= 50-300 $\left.\mathrm{cm}^{-1}\right)$, yüksek dalga sayısı bölgesi $\left(=300-1250 \mathrm{~cm}^{-1}\right)$ ve OH-gerilme bölgesi $\left(=3500-3750 \mathrm{~cm}^{-1}\right)$ şeklinde alt bölümlere ayırmıştır. Araştırmacılar, gelen lazer polarizasyonunun dilinim düzlemine paralel (//) (Şekil 3.a) ya da dik $(\perp)$ (Şekil 3.b) olmasına göre oluşan muskovit Raman spektralarındaki farklılıkları ortaya koymuşlardır. 

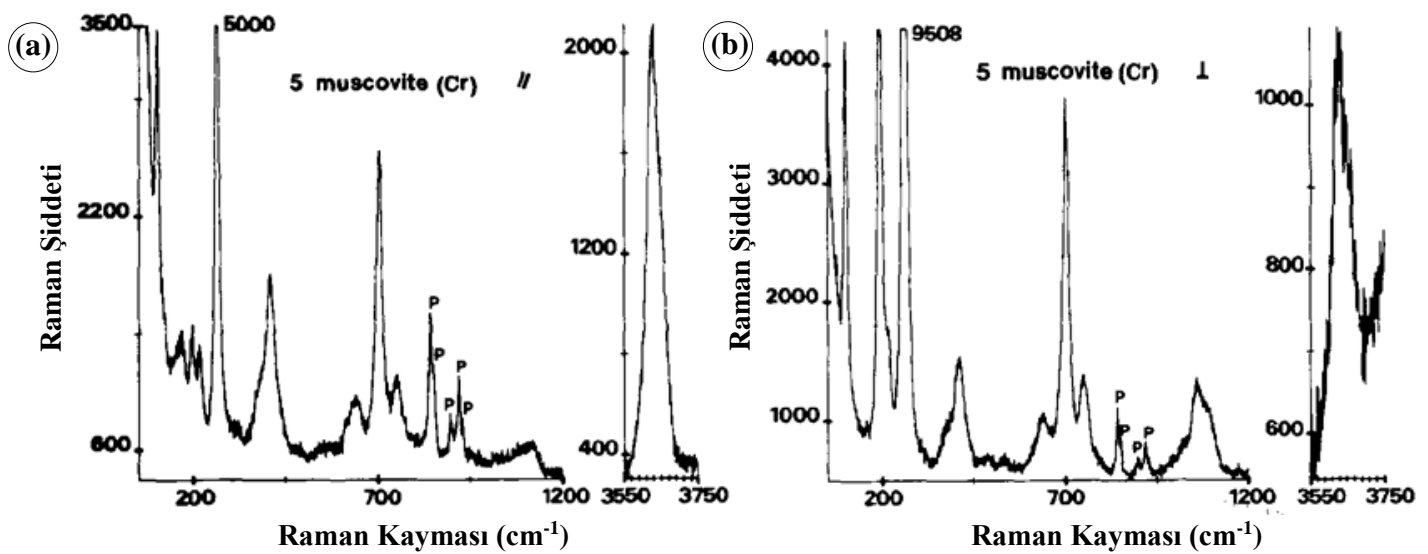

Şekil 3. Muskovitlerin Raman spektrası (gelen lazer polarizasyonu (a): dilinim düzlemine paralel, (b): dilinim düzlemine dik; P: mikroskop objektifinden kaynaklanan parazitleri belirtir) (Tlili ve ark. (1989)'dan alınmıştır)

McKeown ve ark. (1999a)'ya göre; muskovitlerin 800 cm$^{-1}$ 'den daha büyük frekanslarda hesaplanan Raman ve IR-aktif modları, T'nin tetrahedral bir bölge olduğu iç levha T-O gerilmesi ve T-O-T bükülme hareketleri tarafindan domine edilmiştir. 800 ve $360 \mathrm{~cm}^{-1}$ arasındaki modlar, $\mathrm{K}$ ve oktahedral Al yer değiştirmeleri ile karışık iç tetrahedral levha hareketlerine sahiptir. $360 \mathrm{~cm}^{-1}$, den daha düşük frekanslardaki modlar ise, kafes ve $\mathrm{OH}$ hareketlerine sahiptir (Şekil 4).

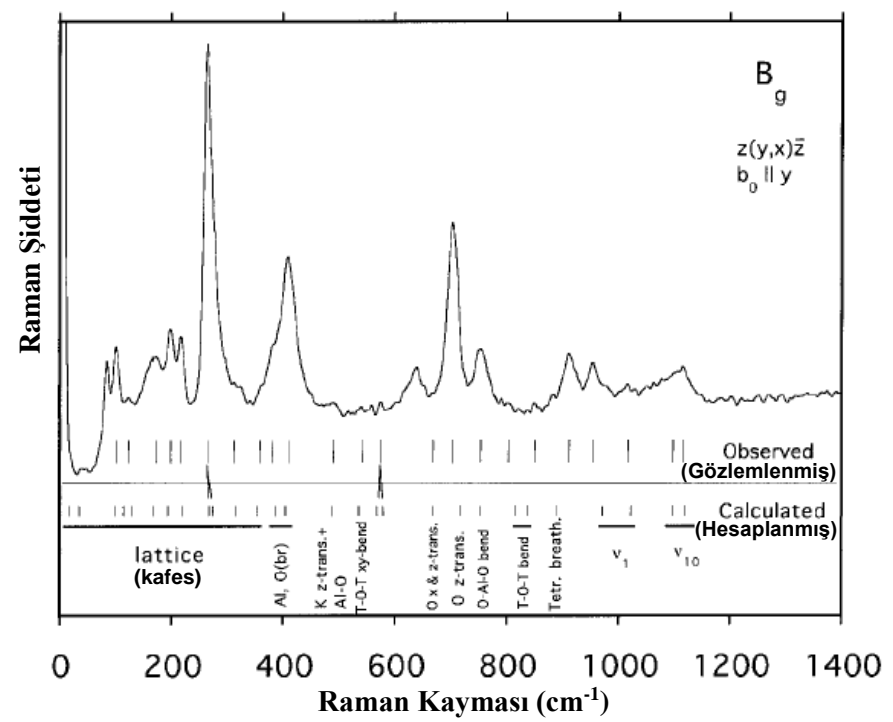

Şekil 4. Muskovit için Bg simetrisinin Raman spektrumu (McKeown ve ark. (1999a)'den alınmıştır).

Wang ve ark. (2002), fillosilikatların Raman spektroskopik karakterizasyonunu inceledikleri çalışmada; muskovitlerin tipik Raman spektrasını vermişlerdir (Şekil 5).

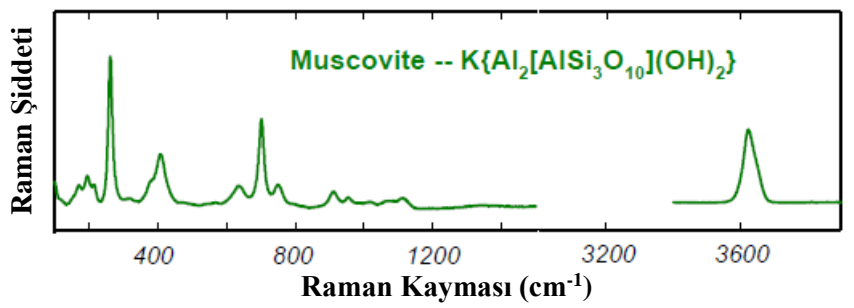

Şekil 5. Muskovitin tipik Raman spektrası (Wang ve ark. (2002)'den değiştirilerek alınmıştır) 
Šontevska ve ark. (2008)'in titreşimsel spektroskopik özelliklerinin bazı fillosilikat mineralleri için tanımlayıcı araç olarak kullanılabilirliğini irdeledikleri çalışmada muskovitlerin Raman spektrasındaki bantları açıklamışlardır. Bu çalışmaya göre; yüksek frekanslı (yaklaşık $1100 \mathrm{~cm}^{-1}$ ) geniş ve karmaşık bant ve $900 \mathrm{~cm}^{-1}$ civarındaki bant, $\mathrm{Si}-\mathrm{O}-\mathrm{Si}(\mathrm{Al})$ gerilme titreşimlerini temsil etmektedir. Daha düşük dalga sayılarına doğru gidildikçe, 750 ve $700 \mathrm{~cm}^{-1}$ civarındaki çok zayıf bant muhtemelen $\delta(\mathrm{O}-\mathrm{Al}-\mathrm{O})$ titreşimlerinden kaynaklanmaktadır. Dunje’den (Kuzey Makedonya) alınan muskovitin sadece Fourier Dönüşümlü (FT) Raman spektrumunda kayıtlı olan $541 \mathrm{~cm}^{-1}$ 'deki bant, McKeown ve ark. (1999a)'ya göre Al-O-Al bükülme karakterine sahiptir. 420 ve $260 \mathrm{~cm}^{-1}$ civarındaki daha düşük frekans bantları, yalnızca tek bir titreşim tipine atanamaz ve esas olarak O-Al-O ve O-Si-O translasyonlarıyla ilişkilendirilen karışık karaktere sahiptir. 190 $\mathrm{cm}^{-1}$ 'deki Raman piki, Al-OH translasyonlarına bağlanabilir (Šontevska ve ark., 2008).

Singh ve Singh (2016)'nın tabakalı fillosilikatlardan muskovit ve biyotitlerin titreşimsel spektroskopik özelliklerini ve elektron mikroprob, XRD ve IR spektroskopik gibi farklı tekniklerle kombinasyonunu inceledikleri çalışmada muskovitlerin literatürdeki farklı kökenlerdeki muskovitler ile karşılaştırarak Raman bantlarını açıklamışlardır. Buna göre; yüksek frekans bölgesinde, $1127 \mathrm{~cm}^{-1}$ civarında çok güçlü bir bant ve $914 \mathrm{~cm}^{-1}$ civarında orta şiddetli bant, Si-O-Si ve Si-O-Al gerilme titreşimlerine aittir. $755 \mathrm{~cm}^{-1}$ ve $703 \mathrm{~cm}^{-1}$ civarındaki orta şiddet band1, $\delta(\mathrm{O}-\mathrm{Al}-\mathrm{O})$ titreşimlerinden kaynaklanmaktadır. Al-O-Al'in bükülme özelliğinden dolayı muskovitin Raman spektrumunda $579 \mathrm{~cm}^{-1}$ ’lik bir bant gözlenmektedir. $407 \mathrm{~cm}^{-1}$ ve 263 $\mathrm{cm}^{-1}$ civarındaki düşük frekanslı güçlü bantlar, O-Al-O ve O-Si-O translasyonlarıyla bağlantılıdır. Al-OH translasyonları nedeniyle, $197 \mathrm{~cm}^{-1}$ civarında orta şiddetli bir Raman piki de gözlenir (Singh ve Singh, 2016).

\section{Materyal ve Metot}

$\mathrm{Bu}$ çalışma; literatür taraması, arazi çalışması, laboratuvar çalışması ve elde edilen tüm verilerin değerlendirilmesi aşamalarından oluşmaktadır.

YİK'nin kuzey bölümünde yer alan beyaz mika içeren granitlerde yapılan arazi çalışması sonucunda alınan kaya örneklerinden üstü açık parlak ince kesitler yaptırılmış olup ayrıntılı mineralojik ve petrografik incelemeler neticesinde mineralojik bileşimleri ve mikroskobik dokusal özellikleri ortaya konmuştur. Petrografik incelemeler, Ankara Üniversitesi Yer Bilimleri Uygulama ve Araştırma Merkezi’nde (YEBİM) Leica marka DMLP model polarizan mikroskop kullanılarak yapılmışır.

Petrografik inceleme neticesinde S-tipi granitleri temsil eden kaya örneklerinden seçilen beyaz mikaların Raman spektroskopik karakteristikleri incelenmiştir. KRS incelemesi, YEBİM laboratuvarlarında yüksek çözünürlüklü “Thermo Scientific DXR” model konfokal Raman spektrometresi kullanılarak yapılmıştır. Parlak ince kesitler üzerinde yerleri belirlenerek işaretlenmiş olan beyaz mikaların (muskovitlerin), slit açıklı̆̆ $25 \mu \mathrm{m}$ ve 600 çizgi/mm grating değerli (tahmini çözünürlük: 2,6-4,4 $\mathrm{cm}^{-1}$ ve tahmini nokta boyutu: $0,7 \mu \mathrm{m}$ ) $633 \mathrm{~nm}$ dalga boyunda lazer ile uyarılarak yapılan Raman spektroskopik ölçümleri neticesinde $50-1250 \mathrm{~cm}^{-1}$ ve $2800-3623 \mathrm{~cm}^{-1}$ dalga sayısı aralıklarındaki spektrumları elde edilmiştir.

Literatür araştırması, arazi ve laboratuvar çalışmaları sonucunda elde edilen veriler hep birlikte değerlendirilerek çalışma alanındaki S-tipi granitlerdeki beyaz mikaların ayırt edilmesini sağlayan kriterler bu çalışmada saptanmaya çalışılmıştır. 


\section{Bulgular ve Tartışma}

\section{Petrografi}

YİK’nin kuzey bölümünde tipik olarak Sarıhacılı ve civarında yayılım gösteren S-tipi granitler, açık pembe renkli, daha çok lökokrat karakterde ve alkali feldispat granit bileşimine sahiptirler (Akçe, 2003; Akçe ve Kadıŏlu, 2004; Akçe ve Kadıŏlu, 2005).

Yer yer iri kuvarslar içeren birim, faneritik ve iri kuvarslardan dolayı porfiro faneritik doku özelliği sergilemektedir (Şekil 6.a).

Polarizan mikroskop altında holokristalin hipidiyomorf doku özelliği sergileyen bu granitik kayalar başlıca kuvars, alkali feldispat, beyaz ve siyah mika (muskovit ve biyotit) ve az oranda plajiyoklaz mineralleri içerirler (Şekil 6.b). Beyaz mikalar petrografik incelemelerde genel olarak sergiledikleri levhamsı biçimli, renksiz, düşük rölyefli ve tek yönlü dilinimli olması, canlı girişim renkleri ile karakteristiktirler. İncelenen kayalarda tali mineral olarak genelde özşekilsiz ve yarı özşekilli granatlar da az oranda bulunmaktadır.
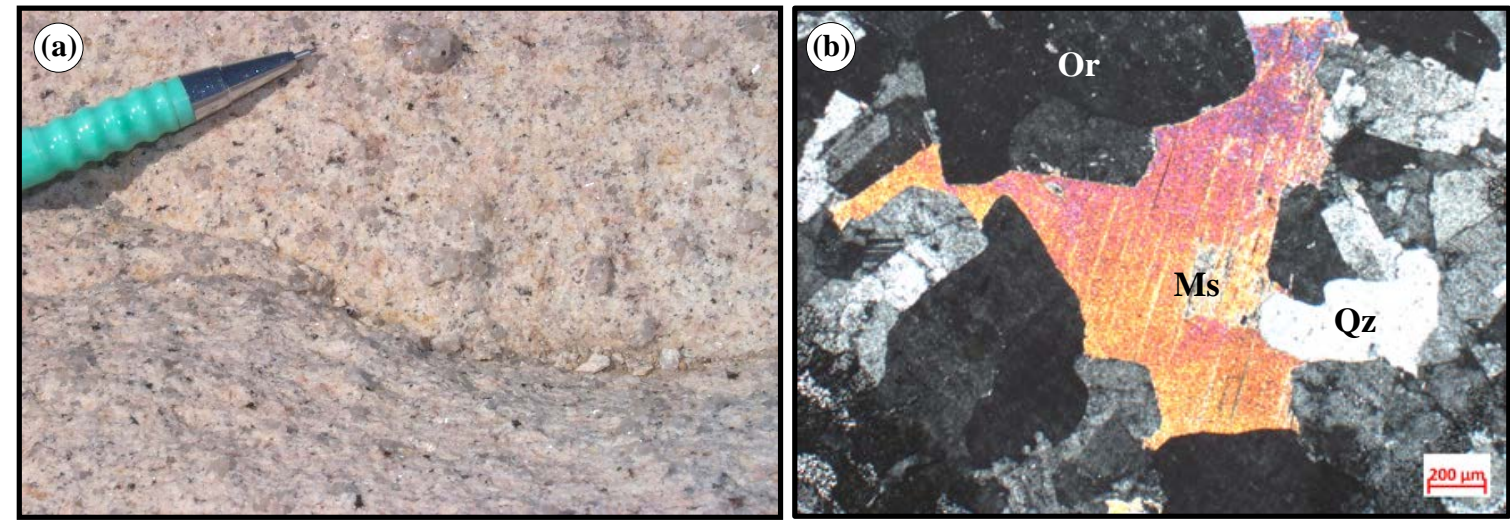

Şekil 6. Yozgat İntrüzif Kompleksi kuzeyindeki S-tipi granitlerin (a): arazi görüntüsü, (b): polarizan mikroskop görüntüsü (çapraz nikol; Qz: kuvars, Or: ortoklaz, Ms: muskovit; mineral kısaltmaları Whitney ve Evans (2010)’a göre yapılmıştır)

Bu felsik intrüzif kayalar, modal mineralojik bileşimlerine göre QAPF adlandırma diyagramında (Streckeisen, 1976) alkali feldispat granit bileşimi sergilemektedirler.

\section{Konfokal Raman Spektroskopisi}

YİK’nin kuzey bölümündeki S-tipi granitler içerisindeki beyaz mikalar muskovit bileşiminde ve genelde temiz yüzeyli olup referans spektra ile uyumlu ve güçlü Raman bantları sergilemektedirler (Şekil 7).

Muskovit mikaların Raman karakteristikleri ile ilgili literatürde birçok araştırmacı tarafından yapılan çalışmalar mevcuttur. Çalışma alanındaki granitler içerisindeki beyaz mikaların (muskovitlerin) Raman spektrumundaki ve literatürde yayımlanmış farklı bölgelere ait muskovitlerin spektral sonuçlarının farklı bantlar için belirlenmiş deneysel sonuçları karşılaştırmalı olarak Tablo 2'de verilmiştir. Bu çalışmada incelenen beyaz mikalar için elde edilen Raman sonuçları, farklı kökenlerden muskovit mikalarla ilgili literatürde yayınlanmış verilerle genel olarak uyumlu olup pikler açısından örtüşme göstermektedir. Uyumlu olmayanlar bazı minör pikler de görülmektedir. Bu durum, incelenen minerallerin oluşum sıcaklık ve basınç koşullarındaki farklılıklardan kaynaklanabilmektedir. 

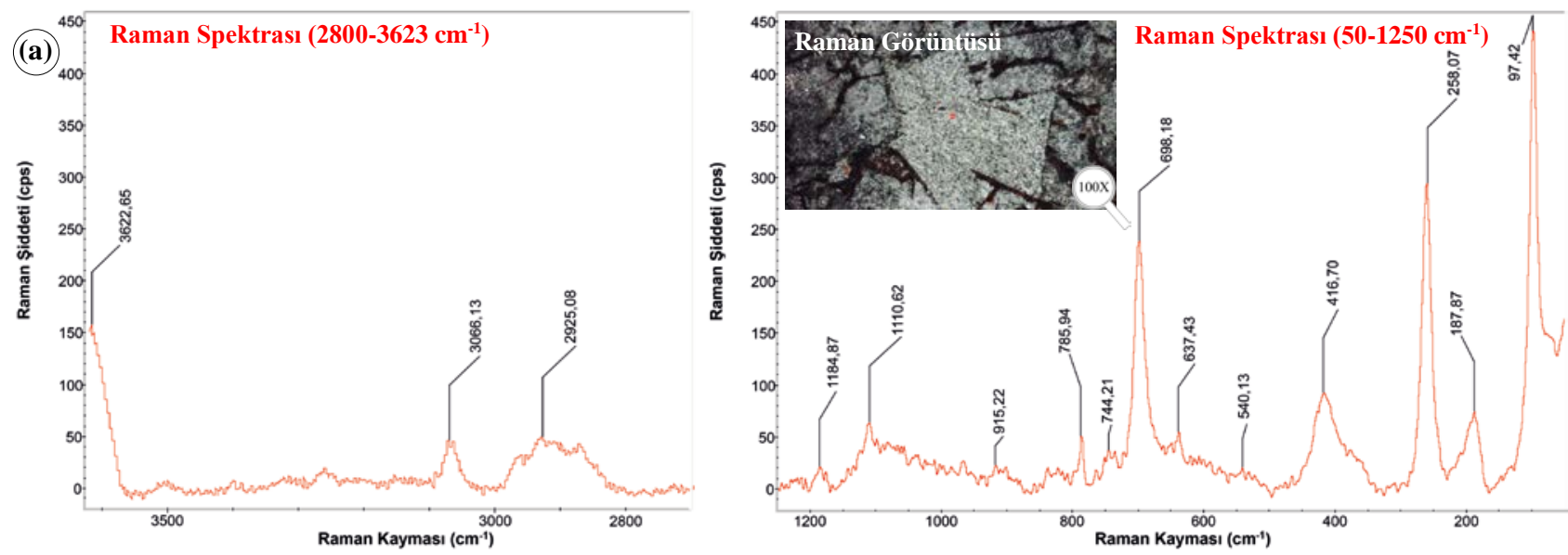

(b)
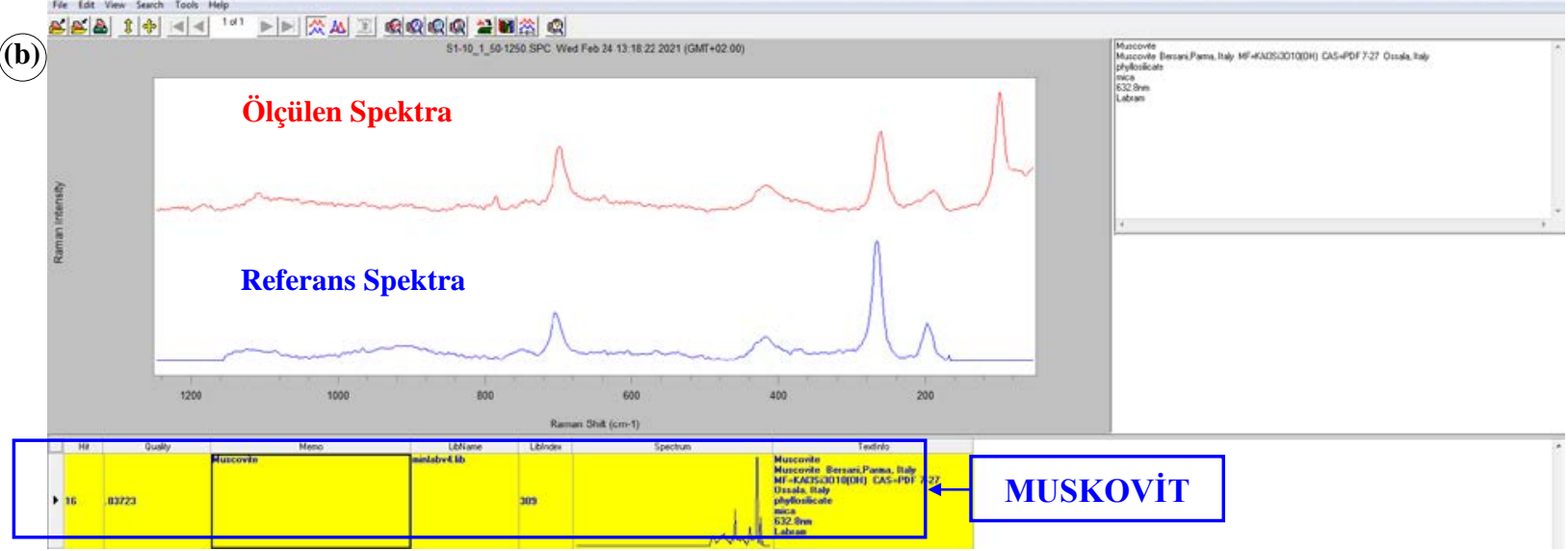

Şekil 7. Yozgat İntrüzif Kompleksi kuzey bölümündeki S-tipi granitler içerisindeki muskovitlerin Raman spektroskopik karakteristikleri: (a) doğrudan ölçülen spektrumlar, (b) ölçülen pik ile referans pikin karşılaştırılması.

Tablo 2. Muskovitin Raman spektrasındaki farklı araştırmacılarca belirlenmiş bantlar ve açıklamaları

\begin{tabular}{|c|c|c|c|c|c|c|c|c|c|}
\hline Bu çalışma & $\begin{array}{l}\text { Singh ve } \\
\text { Singh, } 2016 \\
\text { (Nilore) }\end{array}$ & $\begin{array}{c}\text { Šontevska ve } \\
\text { ark., 2008 } \\
\text { (Dunje) }^{\mathrm{a}}\end{array}$ & $\begin{array}{c}\text { Šontevska ve } \\
\text { ark., 2008 } \\
\text { (Dunje) }^{b}\end{array}$ & $\begin{array}{c}\text { Šontevska ve } \\
\text { ark., 2008 } \\
\text { (Nežilovo) }^{\mathrm{a}}\end{array}$ & $\begin{array}{c}\text { Šontevska ve } \\
\text { ark., 2008 } \\
\text { (Nežilovo) }^{\mathrm{a}}\end{array}$ & $\begin{array}{c}\text { Wopenka } \\
\text { ve ark., } \\
2002\end{array}$ & $\begin{array}{c}\text { McKeown } \\
\text { ve ark., } \\
\text { 1999a }\end{array}$ & $\begin{array}{c}\text { Wada ve } \\
\text { Kamitakahara, } \\
1991\end{array}$ & $\begin{array}{l}\text { Deneysel } \\
\text { Modlar }\end{array}$ \\
\hline $1111^{\mathrm{m}}$ & $1127^{\mathrm{Vs}}$ & $1097^{\mathrm{VW}, \mathrm{br}}$ & $1102^{\mathrm{W}}$ & $1097^{\mathrm{W}}$ & - & - & $1098^{\mathrm{W}}$ & - & $v(\mathrm{Si}-\mathrm{O}-\mathrm{Si})$ \\
\hline $915^{\mathrm{vw}}$ & $914^{\mathrm{m}}$ & $900^{\mathrm{VW}}$ & $899^{w}$ & $902^{\mathrm{VW}}$ & $902^{\mathrm{Vw}}$ & $914^{\mathrm{w}}$ & $912^{\mathrm{w}}$ & $895^{\mathrm{w}}$ & $v(\mathrm{Si}-\mathrm{O}-\mathrm{Al})$ \\
\hline $744^{\mathrm{w}}$ & $755^{\mathrm{m}}$ & $752^{\mathrm{VW}}$ & $753^{\mathrm{vw}}$ & $751^{\mathrm{vw}}$ & $752^{\mathrm{vw}}$ & $756^{\mathrm{w}}$ & $754^{\mathrm{w}}$ & $755^{\mathrm{vw}}$ & $\delta(\mathrm{O}-\mathrm{Al}-\mathrm{O})$ \\
\hline $698^{s}$ & $703^{s}$ & $703^{s}$ & $701^{s}$ & $701^{s}$ & $698^{\mathrm{m}}$ & $706^{\mathrm{s}}$ & $704^{\mathrm{s}}$ & $705^{\mathrm{s}}$ & $\delta(\mathrm{O}-\mathrm{Al}-\mathrm{O})$ \\
\hline $540^{\mathrm{Vw}}$ & $579^{\mathrm{VW}}$ & - & $541^{\mathrm{w}}$ & - & - & $566^{\mathrm{W}}$ & $542^{\mathrm{w}}$ & - & $\delta(\mathrm{Al}-\mathrm{O}-\mathrm{Al})$ \\
\hline $417^{\mathrm{m}, \mathrm{br}}$ & $407^{\mathrm{s}}$ & $419^{\mathrm{m}, \mathrm{br}}$ & $420^{\mathrm{m}, \mathrm{br}}$ & $420^{\mathrm{m}}$ & $420^{w}$ & $417^{\mathrm{S}}$ & $410^{\mathrm{s}}$ & $425^{\mathrm{s}}$ & $\delta(\mathrm{O}-\mathrm{Al}-\mathrm{O})$ \\
\hline $258^{\mathrm{VS}}$ & $263^{\mathrm{vs}}$ & $262^{\mathrm{vs}}$ & $262^{\mathrm{vs}}$ & $262^{\mathrm{S}}$ & $262^{s}$ & $263^{\mathrm{vs}}$ & $265^{\mathrm{vs}}$ & $270^{\mathrm{vs}}$ & $\delta(\mathrm{O}-\mathrm{Si}-\mathrm{O})$ \\
\hline $188^{\mathrm{m}}$ & $197^{\mathrm{m}}$ & $191^{\mathrm{m}}$ & $191^{\mathrm{m}}$ & $188^{\mathrm{w}}$ & $188^{\mathrm{w}}$ & $195^{\mathrm{m}}$ & $199^{\mathrm{m}}$ & $200^{\mathrm{m}}$ & $\mathrm{L}(\mathrm{Al}-\mathrm{OH})$ \\
\hline
\end{tabular}

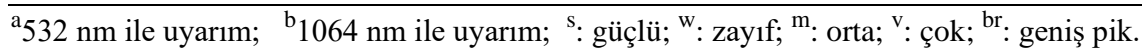

İncelenen muskovit mikaların 50-1250 $\mathrm{cm}^{-1}$ bölgesindeki Raman spektrumu Şekil 7.a'da verilmiştir. Yüksek frekans bölgesinde 1110,62 $\mathrm{cm}^{-1}$ deki orta şiddetli, geniş ve asimetrik bant $\mathrm{Si}-\mathrm{O}-\mathrm{Si}$ gerilme titreşimlerine; $915,22 \mathrm{~cm}^{-1}$ 'deki çok zayıf şiddetli bant ise Si-O-Al gerilme titreşimlerine aittir. $785,94 \mathrm{~cm}^{-1}$ 'deki bant tetrahedral titreşimleri (T-O-T bükülme hareketlerini) temsil eder. 744,21 $\mathrm{cm}^{-1}$ 'deki zayıf şiddetli bant ile 698,18 cm ${ }^{-1}$ 'deki güçlü bant $\mathrm{O}-\mathrm{Al}-\mathrm{O}$ bükülme titreşimlerinden kaynaklanır. $540,13 \mathrm{~cm}^{-1}$ 'deki çok zayıf şiddetli bantın McKeown ve ark. (1999a)'ya göre Al-O-Al bükülme karakterine sahip olduğu söylenebilir. 
Düşük frekans bölgesinde $416,70 \mathrm{~cm}^{-1}$, deki orta şiddetli ve geniş bant ile $258,07 \mathrm{~cm}^{-1}$, deki çok güçlü bant, sırasıyla O-Al-O ve O-Si-O translasyonları ile bağlantılıdır. 187,87 cm-1'deki orta şiddetli ve asimetrik bant Al-OH translasyonlarına bağlıdır. En düşük frekans olan $97,42 \mathrm{~cm}^{-1}$, deki çok güçlü bant, McKeown ve ark. (1999a)'ya göre levha translasyonlarından kaynaklanmaktadır.

İncelenen muskovit mikaların 2800-3623 cm-1 bölgesindeki Raman spektrumu Şekil 7.a'da verilmiştir. Literatürde belirtildiği üzere $3800-3000 \mathrm{~cm}^{-1}$ spektral bölgesindeki Raman pikleri fillosilikatların yapılarındaki $\mathrm{OH}$ ya da suyun gerilme modundan kaynaklanmaktadır (Wang ve ark., 2002, 2015). 3100-2800 $\mathrm{cm}^{-1}$ spektral bölgesindeki Raman pikleri ise C-H gerilme titreşimlerine aittir (Fries ve Steele, 2018; Larkin, 2011). 3622,65 $\mathrm{cm}^{-1}$ 'deki güçlü bant literatürde muskovit mikalar için belirtilen tipik $\mathrm{OH}$ gerilme modu ile birebir uyumludur (Tlili ve ark., 1989; Wang ve ark., 2002). 2800-3623 cm-1 arasındaki Raman bantları, O-H ve C-H gerilme titreşimlerinden kaynaklanan bantlarla örtüşme yapabilmektedir (Socrates, 2001). Raman spektral yorumlamalarda bu bantlara dikkat edilmesi gerekmekte ve ayırımının yapılabilmesi önem taşımaktadır.

\section{Sonuçlar}

Beyaz mikaların, magmatik kayalar içerisinde tipik olarak alkali feldispat granitlerde ve pegmatitlerde oluştuğu belirlenmiştir. Bu çalışma kapsamında, Raman spektroskopik özelliklerini kullanarak muskovit bileşimindeki beyaz mikaların diğer mikalardan ayırt edilmesi konusu ele alınmıştır. Oluştuğu ortam itibarıyla beyaz mikaların kendine has Raman kayma spektrumları ve kayma değerleri ortaya konulmuştur. Aynı zamanda bulunduğu ortam itibarıyla, sıkışmalı tektonik rejime bağlı kaldığı zaman Raman piklerinde kaymaların oluşabileceği tespit edilmiştir.

Sonuç olarak; muskovitler bulunduğu kaya bakımından magmatik, metamorfik ve sedimanter kökenini belirlemeye yönelik olarak Raman kayma değerlerindeki farklılıklar karakteristik olarak kullanılabilirler. Böylece S-tipi granitlerdeki muskovitlerin diğer granit ve farklı kayalardaki muskovitlerden ayırt edilmesi için Raman spektrumlarının karakteristik olarak belirlenebileceği ortaya konulmuştur.

\section{Çıkar Çatışması Beyanı}

Makale yazarları aralarında herhangi bir çıkar çatışması olmadığını beyan ederler.

\section{Araştırmacıların Katkı Oranı Beyan Özeti}

Yazarlar makaleye eşit oranda katkı sağlamış olduklarını beyan ederler.

\section{Kaynakça}

Akçe MA. Yozgat Batolitinin kuzey bölümünün jeolojisi ve petrolojisi. Ankara Üniversitesi Fen Bilimleri Enstitüsü Yüksek Lisans Tezi, sayfa no:118, Ankara, Türkiye, 2003.

Akçe MA. Yozgat İntrüzif Kompleksinin jeolojisi, petrolojisi ve Orta Anadolu Kristalen Karmaşığındaki zamansal ve mekansal konumu. Ankara Üniversitesi Fen Bilimleri Enstitüsü Doktora Tezi, sayfa no:240, Ankara, Türkiye, 2010. 
Akçe MA., Kadığlu YK. Petrology of s-type granites and gabbros of Yozgat Batholith: Central Anatolian Crystalline Complex. Geochimica et Cosmochimica Acta 2004; 68(11) Suppl. 1: A659.

Akçe MA., Kadığlu YK. Yozgat batoliti kuzey bölümündeki lökogranitlerin petrolojisi. Türkiye Jeoloji Bülteni 2005; 48(2): 1-20.

Akçe MA., Kadığlu YK. Yozgat İntrüzif Kompleksindeki granatların Raman konfokal spektroskopik karakteristikleri. 62. Türkiye Jeoloji Kurultay1, 13-17 Nisan 2009a, sayfa no:614-615, Ankara.

Akçe MA., Kadığlu YK. Raman spektroskopisinin mineralojide kullanımı: Yozgat İntrüzif Kompleksi, Orta Anadolu. XI. Ulusal Spektroskopi Kongresi, 23-26 Haziran 2009b, sayfa no:14, Ankara.

Akçe MA., Kadığlu YK. Raman spektroskopisinin ilkeleri ve mineral tanımlamalarında kullanılması. Nevşehir Bilim ve Teknoloji Dergisi 2020; 9(2): 99-115.

Blaha JJ., Rosasco GJ. Raman microprobe spectra of individual microcrystals and fibers of talc, tremolite, and related silicate minerals. Analytical Chemistry 1978; 50(7): 892-896.

Boztuğ D. Kırşehir Bloğundaki Yozgat batoliti doğu kesiminin (Sorgun Güneyi) petrografisi, ana element jeokimyası ve petrojenezi. İstanbul Üniversitesi Mühendislik Fakültesi Yerbilimleri Dergisi 1994; 9 (12): $1-20$.

Chukanov NV., Vigasina MF. Vibrational (Infrared and Raman) spectra of minerals and related compounds. 1st ed. Springer Mineralogy Series. Cham, Switzerland: Springer; 2020.

Smith E., Dent G. Modern Raman spectroscopy: a practical approach. 2nd ed. Hoboken, NJ, USA: Wiley; 2019.

Deniz K. Buzlukdağı (Kırşehir) alkali magmatik kayaçların jeolojisi, petrolojisi ve konfokal Raman spektrometresi ile incelenmesi. Ankara Üniversitesi Fen Bilimleri Enstitüsü Yüksek Lisans Tezi, sayfa no:138, Ankara, Türkiye, 2010.

Deniz K. Mica types as indication of magma nature, Central Anatolia, Turkey. Acta Geologica Sinica - English Edition 2021; doi: https://doi.org/10.1111/1755-6724.14670.

Deniz K., Kadığlu YK. Investigation of feldspar raw material potential of alkali feldspar granites and alkali feldspar syenites within Central Anatolia. Bulletin of the Mineral Research and Exploration 2019; 158: 265-289.

Deniz K., Kadığlu YK., Koralay T., Güllü B., Akçe MA., Kılıç CO. Petrology and Raman characterization of leucitites within the ultrapotassic rocks: Afyon, NW Turkey. Mineralogical Magazine 2013; 77(5): 974.

Ekici T., Boztuğ D. Anatolid-Pontid çarpışma sisteminin pasif kenarında yer alan Yozgat Batolitinde synCOLG ve post-COLG granitoyid birlikteliği. Yerbilimleri 1997; 30(1): 519-538.

Erler A., Göncüoğlu MC. Geologic and tectonic setting of the Yozgat Batholith, Northern Central Anatolian Crystalline Complex, Turkey. International Geology Review 1996; 38(8): 714-726.

Farmer VC. Differing effects of particle size and shape in the infrared and Raman spectra of kaolinite. Clay Minerals 1998; 33(4): 601-604.

Foucher F., Guimbretière G., Bost N., Westall F. Petrographical and mineralogical applications of Raman mapping. In: Maaz, K. (ed.) Raman spectroscopy and applications. InTechOpen 2017; 163-180. 
Foucher F., Lopez-Reyes G., Bost N., Rull-Perez F., Rüßmann P., Westall F. Effect of grain size distribution on Raman analyses and the consequences for in situ planetary missions. Journal of Raman Spectroscopy 2013; 44(6): 916-925.

Fries M., Steele A. Raman spectroscopy and confocal Raman imaging in mineralogy and petrography. In: Toporski, J., Dieing, T., Hollricher, O. (eds.) Confocal Raman microscopy. Springer Series in Surface Sciences, Springer International Publishing 2018; 66: 209-236.

Frost RL. Fourier transform Raman spectroscopy of kaolinite, dickite and halloysite. Clays and Clay Minerals 1995; 43(2): 191-195.

Frost RL., Kloprogge JT. Raman spectroscopy of nontronites. Applied Spectroscopy 2000; 54(3): 402-405.

Frost RL., Rintoul L. Lattice vibrations of montmorillonite: an FT Raman and X-ray diffraction study. Applied Clay Science 1996; 11(2-4): 171-183.

Frost RL., Van der Gaast SJ. Kaolinite hydroxyls - a Raman study. Clay Minerals 1997; 32(3): 471-484.

Göncüoğlu MC., Toprak V., Kuşcu İ., Erler A., Olgun E. Orta Anadolu Masifinin Batı bölümünün jeolojisi, Bölüm 1: Güney kesim. TPAO, 1991; Rapor No: 2909 (yayımlanmamış).

Görür N., Oktay FY., Seymen İ., Şengör AMC. Palaeotectonic evolution of the Tuzgölü basin complex, Central Turkey: sedimentary record of a Neo-Tethyan closure. In: Dixon J.E., Robertson A.H.F. (eds) The geological evolution of the Eastern Mediterranean. Geological Society, London, Special Publications 1984; 17: 467-482.

Griffith WP. Raman spectroscopy of minerals. In: Farmer, V.C. (ed.) The infrared spectra of minerals. Mineralogical Society Monograph, London: Mineralogical Society; 1974; 4: 119-135.

Güllü B., Kadığlu YK. Orta Anadolu'daki farklı turmalinlerin konfokal Raman spektrometrisi ile tanımlanması. 62. Türkiye Jeoloji Kurultayı, 13-17 Nisan 2009, sayfa no:630-631, Ankara.

Güllü B., Kadıoğlu YK. Use of tourmaline as a potential petrogenetic indicator in the determination of host magma: CRS, XRD and PED-XRF methods. Spectrochimica Acta Part A: Molecular and Biomolecular Spectroscopy 2017; 183: 68-74.

Güllü B., Kadığlu YK., Koralay T., Deniz K. Raman characteristics of Gücünkaya (Aksaray) gabbroic rocks, Central Anatolia-Turkey. 19 $9^{\text {th }}$ International Multidisciplinary Scientific GeoConference SGEM 2019, 30 June - 6 July 2019, 19(1.1): page number:475-482, Bulgaria.

Kadığlu YK., Dilek Y., Foland KA. Slab break-off and syncollisional origin of the Late Cretaceous magmatism in the Central Anatolian crystalline complex, Turkey. In: Dilek Y., Pavlides S. (eds) Postcollisional tectonics and magmatism in the Mediterranean region and Asia. Special Papers Geological Society of America 2006; 409: 381-415.

Kadıoğlu YK., Deniz K., Koralay T., Güllü B. Nature of the gabbro in Central Anatolia: geological observation and spectroscopic applications, Turkey. $19^{\text {th }}$ International Multidisciplinary Scientific GeoConference SGEM 2019, 30 June - 6 July 2019, 19(1.1): page number:377-384, Bulgaria.

Kadığlu YK., Koralay T., Zoroğlu O., Güllü B., Akçe MA., Deniz K., Yıldırım B. Differentiation of ophiolitic and nonophiolitic gabbros using confocal Raman spectroscopy: Central Anatolia Turkey. Mineralogical Magazine 2011; 75(3): 1133. 
Ketin İ. Yozgat bölgesinin jeolojisi ve Orta Anadolu Masifinin tektonik durumu. Türkiye Jeoloji Kurumu Bülteni 1955; 6(1): 1-28.

Kloprogge JT., Frost RL. The effect of synthesis temperature on the FT-Raman and FT-IR spectra of saponites. Vibrational Spectroscopy 2000; 23(1): 119-127.

Koralay T., Kadığlu YK., Jiang SY. Determination of tourmaline composition in pegmatite from Buldan, Denizli (Western Anatolia, Turkey) using XRD, XRF, and confocal Raman spectroscopy. Spectroscopy Letters 2013; 46(7): 499-506.

Koralay T., Ören U. Determination of spectroscopic features and gemstone potential of garnet crystals from the Çamköy region (Aydın - SW Turkey) using XRPD, XRF, confocal Raman spectroscopy, EPMA and gemological test methods. Periodico di Mineralogia 2020; 89(2): 105-123.

Larkin PJ. Infrared and Raman spectroscopy: principles and spectral interpretation. 1st ed. Waltham, USA: Elsevier; 2011.

Loh E. Optical vibrations in sheet silicates. Journal of Physics C: Solid State Physics 1973; 6(6): 1091-1104.

Lünel AT. An approach to the naming, origin and age of Baranadağ monzonite of the Kırşehir intrusive suite. METU Journal of Pure and Applied Sciences 1985; 18(3): 385-404.

McKeown DA., Bell MI., Etz ES. Vibrational analysis of the dioctahedral mica: $2 M_{1}$ muscovite. American Mineralogist 1999a; 84(7-8): 1041-1048.

McKeown DA., Bell MI., Etz ES. Vibrational analysis of the trioctahedral mica phlogopite. American Mineralogist 1999b; 84(5-6): 970-976.

McMillan PF., Hofmeister, AM. Infrared and Raman spectroscopy. In: Hawthorne, F.C. (ed.) Reviews in mineralogy: spectroscopic methods in mineralogy and geology. Washington, D.C.: Mineralogical Society of America 1988; 18(1): 99-159.

Nasdala L., Smith DC., Kaindl R., Gaft M., Ziemann MA. Raman spectroscopy: analytical perspectives in mineralogical research. In: Beran, A., Libowitzky, E. (eds.) Spectroscopic methods in mineralogy. EMU Notes in Mineralogy, Budapest, Hungary: Eötvös University Press 2004; 6: 281-343.

Norman TN., Gökçen SL., Şenalp M. Sedimentation pattern in Central Anatolia at the Cretaceous-Tertiary boundary. Cretaceous Research 1980; 1(1): 61-84.

Petry R., Mastalerz R., Zahn S., Mayerhöfer TG., Völksch G., Viereck-Götte L., Kreher-Hartmann B., Holz L., Lankers M., Popp J. Asbestos mineral analysis by UV Raman and energy-dispersive X-ray spectroscopy. ChemPhysChem 2006; 7(2): 414-420.

Rinaudo C., Gastaldi D., Belluso E. Characterization of chrysotile, antigorite and lizardite by FT-Raman spectroscopy. The Canadian Mineralogist 2003; 41(4): 883-890.

Robert J-L., Beny J-M., Della Ventura G., Hardy M. Fluorine in micas: crystal-chemical control of the OH-F distribution between trioctahedral and dioctahedral sites. European Journal of Mineralogy 1993; 5(1): 7-18.

Seymen İ. Kaman (Kırşehir) dolayında Kırşehir masifi'nin stratigrafisi ve metamorfizması. Türkiye Jeoloji Kurumu Bülteni 1981; 24(2): 7-14. 
Singh M., Singh L. Vibrational spectroscopic study of muscovite and biotite layered phyllosilicates. Indian Journal of Pure \& Applied Physics 2016; 54: 116-122.

Smith E., Dent G. Modern Raman spectroscopy: a practical approach. 2nd ed. Hoboken, NJ, USA: Wiley; 2019.

Socrates G. Infrared and Raman characteristic group frequencies: tables and charts. 3rd ed. Chichester, England: John Wiley \& Sons; 2001.

Streckeisen A. To each plutonic rock its proper name. Earth Science Reviews 1976; 12(1): 1-33.

Šontevska V., Jovanovski G., Makreski P., Raškovska A., Šoptrajanov B. Minerals from Macedonia. XXI. vibrational spectroscopy as identificational tool for some phyllosilicate minerals. Acta Chimica Slovenica 2008; 55(4): 757-766.

Tatar S., Boztuğ D. Fractional crystallization and magma mingling/mixing processes in the monzonitic association in the SW part of the composite Yozgat Batholith (Şefaatli-Yerköy, SW Yozgat). Turkish Journal of Earth Sciences 1998; 7(3): 215-230.

Tlili A., Smith DC., Beny JM., Boyer H. A Raman microprobe study of natural micas. Mineralogical Magazine 1989; 53(370): 165-179.

Wada N., Kamitakahara WA. Inelastic neutron- and Raman-scattering studies of muscovite and vermiculite layered silicates. Physical Review B 1991; 43(3): 2391-2397.

Wang A., Freeman JJ., Jolliff BL. Understanding the Raman spectral features of phyllosilicates. Journal of Raman Spectroscopy 2015; Special Issue: $11^{\text {th }}$ International GeoRaman Conference, 46(10): 829-845.

Wang A., Freeman J., Kuebler KE. Raman spectroscopic characterization of phyllosilicates. The $33^{\text {rd }}$ Lunar and Planetary Science Conference, March 11-15 2002, \#1374, League City, Texas, USA.

Whitney DL., Evans BW. Abbreviations for names of rock-forming minerals. American Mineralogist 2010; 95(1): 185-187.

Wopenka B., Popelka R., Pasteris JD., Rotroff S. Understanding the mineralogical composition of ancient Greek pottery through Raman microprobe spectroscopy. Applied Spectroscopy 2002; 56(10): 13201328.

Zoroğlu O., Kadığlu YK. Behavior of amphiboles in the determination of magma zoning using confocal Raman spectrometry: Beypazarı Oymaağaç granitoid-Ankara Turkey. The Second International Conference on Geo-Resources in The Middle East and North Africa (GRMENA-2), February 24-28 2007, page number:110-111, Cairo, Egypt. 